\title{
Идентификация и определение биологически активных веществ шалфея лекарственного Salvia officinalis L., полученных в условиях субкритической экстракции
}

\author{
® 2020 Рябоконь Л.П., Милевская В.В., Киселева Н.В., Темердашев 3.А. \\ ФГБОУ ВО «Кубанский государственный университет», Краснодар
}

Поступила в редакцию 20.01.2020 г.

DOI: $10.17308 /$ sorpchrom.2020.20/2376

\begin{abstract}
Объектами исследования были листья шалфея лекарственного (Salvia officinalis L.) из серии «Зеленая аптека», г. Горячий Ключ, Травы Кавказа. Работа посвящена изучению возможности использования альтернативного способа извлечения, идентификации и определения биологически активных веществ из лекарственных трав под воздействием субкритической экстракции. Целью исследований является компонентный состав биологически активных веществ шалфея лекарственного, образующийся в условиях субкритической экстракции. Субкритическая экстракция биологически активных веществ из шалфея лекарственного (Salvia officinalis L.) проводилась с использованием деионизированной воды и 70\% раствора этилового спирта в температурном диапазоне от 100 до $250^{\circ} \mathrm{C}$. Хроматографическое определение аналитов в экстракте шалфея лекарственного проводили методом газовой и жидкостной хромато-масс-спектрометрии в сочетании с техникой твердофазного концентрирования. Идентификацию аналитов осуществляли с использованием стандартных образцов и индивидуальных соединений. Проведена оптимизация условий субкритической и твердофазной экстракции компонентов эфирных масел и фенольных соединений из экстракта шалфея лекарственного. Оптимальный выход эфирномасличных компонентов из шалфея лекарственного достигается при $200^{\circ} \mathrm{C}$, дальнейшее повышение температуры приводит к деградации исследуемых соединений и снижению эффективности их извлечения. Аналиты переводили в органическую фазу твердофазной экстракцией с использованием сорбентов «Strata C18-E», «Strata X», «Oasis HLB». Эфирномасличные и фенольные компоненты в органической фазе получены при субкритической экстракции в условиях повышенных температуры и давлении. Идентифицированный компонентный состав экстракта, образующийся в условиях субкритической экстракции, существенно отличается от веществ, полученных традиционным гидродистилляционным способом. В составе шалфея лекарственного идентифицированы 52 эфирномасличных соединения. Субкритическая экстракция позволила в отличие от гидродистилляционного способа одновременно извлекать компоненты фенольной природы: коричные кислоты, флавоноиды, антоцианы, а также дитерпеновые химические соединения. Достоинством исследуемого способа является возможность одновременного концентрирования и определения эфирномасличных и фенольных компонентов. Результаты данного исследования представляют несомненный интерес для специалистов в области химии лекарственного растительного сырья.
\end{abstract}

Ключевые слова: субкритическая экстракция, шалфей лекарственный, хроматографический анализ, эфирномасличные компоненты, фенольные соединения, концентрирование

\section{Введение}

Лекарственные травы семейства Яснотковые (Lamiaceae) и препараты на их основе широко применяются в современной медицине для лечения ряда заболеваний за счет их антиоксидантных, противоопухолевых, антиканцерогенных, противовоспалительных и антидиабетических свойств [1-3]. Широкий спектр их физиологического действия обусловлен высоким содержанием биологически активных соедине- 
ний, в частности эфирномасличных и фенольных компонентов, антиоксидантов, флавоноидов [4,5].

Для извлечения биологически активных веществ (БАВ) из растительной матрицы обычно применяют способы, описанные в Фармакопее [6]. С другой стороны, состав экстракта, полученный Фармакопейным способом, непостоянен, например, в связи с деградацией некоторых терпеновых спиртов, что затрудняет извлечение термолабильных соединений [7-9]. В настоящее время исследуются возможности использования альтернативных способов извлечения БАВ из лекарственных трав под воздействием микроволновых и ультразвуковых волн, сверхкритической и субкритической экстракций [10-14].

Для идентификации и определения БАВ представляет интерес субкритическая экстракция из растительной матрицы, применение которой обеспечивает высокий выход аналитов при небольшом количестве исходного сырья, а также сокращает время извлечения $[15,16]$.

Целью настоящей работы является идентификация и хроматомассспектрометрическое определение биологически активных веществ шалфея лекарственного Salvia officinalis L., полученных в условиях субкритической экстракции.

\section{Эксперимент}

Реактивы, материалы и используемая аппаратура. Объектами исследования являлись листья шалфея лекарственного (Salvia officinalis L.), серия «Зеленая аптека», г. Горячий Ключ, Травы Кавказа. Перед проведением процедуры экстрагирования биологически активных соединений (БАВ) исходное сырье предварительно сушили воздушно-теневым способом при температуре около $30-40^{\circ} \mathrm{C}$, измельчали и просеивали, выделяя фракции 0.5-1.0 мм, а затем усредняли путем перемешивания.

Идентификацию аналитов осуществляли с использованием стандартов камфена (чистота $\geq 95 \%$ ), $\alpha$-туйона (чистота $\geq 96 \%$ ), $\beta$-линалоола (чистота $\geq 97 \%$ ) и камфоры (чистота $\geq 95 \%$ ) фирмы «Sigma-Aldrich» (США).

Субкритическая экстракция БАВ шалфея лекарственного Salvia officinalis L. проводилась на установке, схема которой описана в [17]. Экстракцию БАВ проводили с использованием деионизированной воды, полученной на установке Milli-Q-UV («Millipore», Франция), а также 70\% раствором этилового спирта (осч, «Вектон»). Для этого навеску измельченного сырья массой 0.20 г набивали в ячейку-экстрактор, которую устанавливали в термостат, подключая ее к капиллярам. 70\%-ный этанол и бидистиллированную воду, выступающие в роли экстрагентов, предварительно продували азотом в течение 10 минут для удаления растворенного кислорода и помещали в емкость для растворителя. С помощью насосной системы заполняли экстракционную ячейку экстрагентом, нагревали систему до заданной температуры при скорости потока растворителя $1 \mathrm{~cm}^{3} /$ мин, после чего собирали $5 \mathrm{~cm}^{3}$ экстракта.

Газохроматографический анализ экстракта реализовывался в сочетании с техникой твердофазного извлечения эфирномасличных компонентов, полученных при субкритической экстракции при повышенных температуре и давлении, в органическую фазу. Для перевода эфирного масла шалфея в органическую фазу, а также очистки от нежелательных компонентов экстракт пропустили через патроны «Strata C18-E», «Strata X», «Oasis HLB», затем элюировали аналиты с патрона органическим растворителем - хлороформом или гексаном. Процесс ТФЭ состоял из трех стадий: кондиционирование патрона с целью его активации, заполнение патрона экстрактом и элюирование целевых компонентов хлороформом/гексаном со скоростью $1 \mathrm{~cm}^{3} /$ мин. В органическую фазу добавляли несколько кристаллов безводного суль- 
фата натрия для осушения. Эффективность ТФЭ аналитов контролировали по степени извлечения производных терпенов, предварительно внося добавки индивидуальных веществ в водные экстракты шалфея на стадии заполнения картриджа.

Хроматографическое определение эфирномасличных компонентов в шалфее лекарственном проводили методом газовой хроматомасс-спектрометрии (ГХ-МС) на газовом хроматографе Shimadzu GC-2010 с масс-спектрометрическим детектором GCMS-QP2010 Plus. Разделение аналитов осуществляли на кварцевой капиллярной колонке HP ULTRA 1 (50 м×0.20 мм, 0.33 мкм) («Agilent Technologies»). Разделение компонентов осуществляли с применением программируемого режима нагрева колонки: $50^{\circ} \mathrm{C}$ (0-3 мин), линейный подъем температуры до $290^{\circ} \mathrm{C}$ со скоростью $8^{\circ} \mathrm{C} /$ мин (3-30 мин) и ее стабилизация в течение 10 мин. Объем вводимой пробы 1 мкл. Начальная температура термостата колонки $-50^{\circ} \mathrm{C}$, температура инжектора $260^{\circ} \mathrm{C}$. В качестве газа-носителя использовали гелий, линейная скорость потока которого составила 25.1 см/мин. Идентификацию эфирномасличных компонентов проводили путем сопоставления полученных масс-спектров, масс-спектров индивидуальных соединений и данных библиотек NIST07, WILEY8 $[18,19]$.

Хроматографическое определение фенольных компонентов в шалфее лекарственном проводили методом жидкостной хроматомасс-спектрометрии (ВЭЖХ-МС) на жидкостном хроматографе «LC 20 Prominence» (Shimadzu, Япония), состоящем из дегазатора DGU-20A5, насоса LC20AD, автоматического дозатора SIL-20A, термостата колонок CTO-20AC, спектрофотометрического детектора на основе диодной матрицы SPD-M20A, квадрупольного масс-детектора LCMS2010EV. Разделение компонентов осуществляли на колонке Luna C18 100A, 250×2.0 мм, 5 мкм (Phenomenex, США) с предколонкой С18 5 мкм, 4х2.0 мм (Phenomenex, США) с использованием градиентного режима элюирования, в качестве подвижной фазы выступала смесь ацетонитрила (А) и воды с добавлением муравьиной кислоты на уровне $0.1 \%$ (В). Режим градиентного элюирования и условия анализа представлены в работе [17]. Градуировочные характеристики в системе ВЭЖХ-ДМД-МС получены для протокатеховой, хлорогеновой, неохлорогеновой, розмариновой, кофейной и карнозоловой кислот, лютеолина-7-О-гликозида, лютеолина-7-O-бета-D-глюкуронид с применением стандартных образцов. Линейность отклика сигнала определялась для 10-11 уровней концентраций протокатеховой, хлорогеновой, неохлорогеновой, кофейной и карнозоловой кислот, лютеолина-7-О-гликозида, а для розмариновой кислоты и лютеолина-7-O-бета-D-глюкуронида - 15 уровней концентраций растворов основного вещества в 70\%-ом этиловом спирте, в каждом случае проводили не менее 3 параллельных измерений одной концентрации раствора, все градуировочные кривые были построены в 6 параллелях, коэффициенты их корреляции составили $\geq 0.999$. Сбор и обработку данных осуществляли с помощью программного обеспечения LCMS Solution (Shimadzu, Япония).

\section{Обсуждение результатов}

Оптимизация субкритической экстракции компонентов эфирных масел из шалфея лекарственного. Для экстракции компонентов эфирных масел из сырья субкритическим способом проводилась оптимизация условий их извлечения, а именно температуры и состава растворителя. Экстракты получали с использованием воды и 70\%-го раствора этилового спирта в воде, выступающих в качестве экстрагентов. Влияние температуры на субкритическую экстракцию эфирномасличных компонентов из шалфея изучали в температурном диапазоне от 100 до $250^{\circ} \mathrm{C}$. Для перевода 
аналитов в органическую фазу применяли твердофазную экстракцию с использованием сорбентов на основе силикагеля с привитыми октадецильными группами.

Установлено, что оптимальным экстрагентом эфирномасличных компонентов шалфея лекарственного в указанном температурном диапазоне при субкритической экстракции является вода. Диаграмма извлечения водой эфирномасличных компонентов шалфея лекарственного при субкритической экстракции при различных температурах приведена на рис. 1.

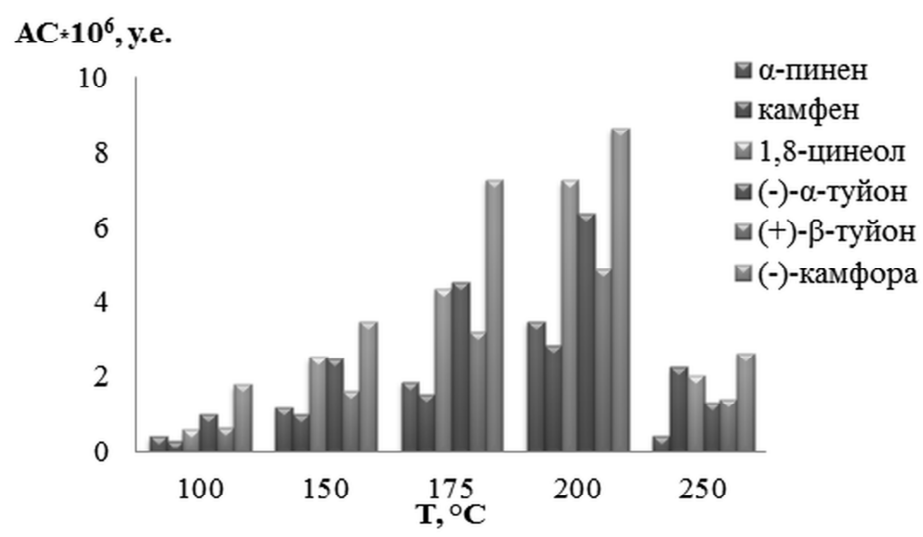

Рис. 1. Диаграмма извлечения эфирномасличных компонентов шалфея лекарственного при различных температурах в условиях субкритической экстракции (экстрагент-вода)

Оптимальный выход эфирномасличных компонентов из шалфея лекарственного при субкритической экстракции достигается при $200^{\circ} \mathrm{C}$, а дальнейшее повышение температуры приводит к деградации исследуемых соединений и, как следствие, снижению эффективности их извлечения.

Оптимизация твердофазной экстракции компонентов эфирных масел из экстрактов шалфея. Для перевода эфирномасличных компонентов шалфея в органическую фазу после субкритической экстракции водный экстракт пропускали через патроны «Strata C18-E», «Strata X», «Oasis HLB», после чего элюировали аналиты с патрона гексаном или хлороформом. Эффективность извлечения аналитов на примере сорбента «Strata C18-E указанными элюентами представлена на рис. 2. Как видно, использование хлороформа значительно повышает степень извлечения терпенов и их производных.

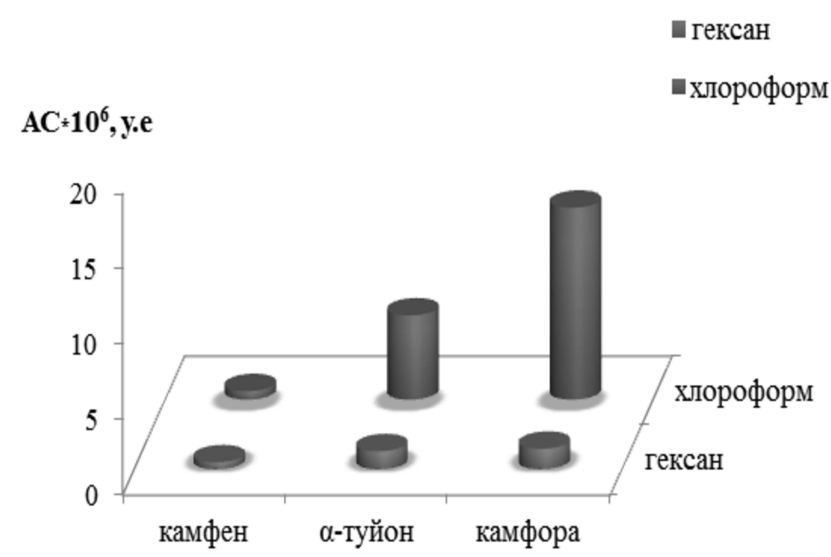

Рис. 2. Сравнение эффективности ТФЭ эфирномасличных компонентов на сорбенте Strata C18-Е гексаном и хлороформом из экстракта, полученного субкритическим способом 
Экстракт эфирномасличных компонентов шалфея, полученный в субкритических условиях, пропускали через сорбенты Strata C18-E, Strata X и Oasis HLB, а затем элюировали аналиты хлороформом, отбирая по 250 или 500 мкл элюата, и анализировали полученные фракции. Определяемые компоненты были зарегистрированы, в основном, в первых 2 фракциях (рис. 3).

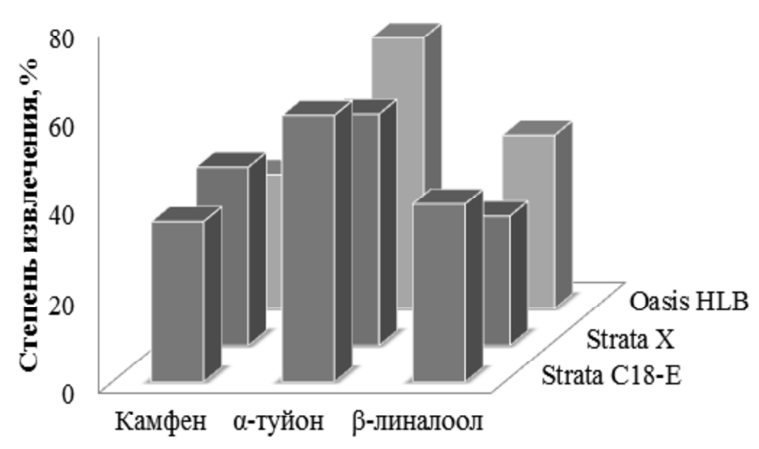

Рис. 3. Степени извлечения эфирномасличных компонентов шалфея, полученных с применением различных сорбентов

Как видно, степень извлечения терпенов и их производных практически сопоставима для всех изучаемых сорбентов и в выбранных условиях сорбции и десорбции не превышает 60\%. Поэтому дальнейшие исследования проводили с использованием патронов Strata C18-E.

Идентификация эфирномасличных компонентов шалфея лекарственного, полученных субкритическим способом, хромато-масс-спектрометрическим методом.

Экстракты, полученные при повышенных температуре и давлении с последующим твердофазным переводом аналитов в органическую фазу, подвергали газохроматографическому анализу. Проведенные исследования показали, что в составе шалфея лекарственного идентифицируются 52 эфирномасличных соединения. Сопоставив полученные данные с результатами ГХ-МС анализа гидродистилляционных экстрактов шалфея лекарственного, представленных авторами [20], можно утверждать, что в условиях субкритической экстракции расширяется спектр идентифицируемых соединений (таблица 1).

Таблица 1. Эфирномасличные компоненты в экстрактах шалфея, полученных в субкритических условиях (СЭ) и гидродистилляцией (ГД)

\begin{tabular}{|c|c|c|c|c|c|c|c|}
\hline № & Соединение & $\begin{array}{c}\text { СЭ, } \\
\text { водой }\end{array}$ & $\begin{array}{l}\text { ГД, } \\
\text { [24] }\end{array}$ & № & Соединение & $\begin{array}{c}\text { СЭ, } \\
\text { водой }\end{array}$ & $\begin{array}{l}\text { ГД, } \\
{[24]}\end{array}$ \\
\hline 1 & 2 & 3 & 4 & 5 & 6 & 7 & 8 \\
\hline 1 & Гептанон - 2 & + & - & 27 & Изотуйонол & + & - \\
\hline 2 & Гептаналь & + & - & 28 & Борнеол & + & + \\
\hline 3 & альфа-Пинен & + & + & 29 & 1-Ундецен & + & - \\
\hline 4 & бета-о-Цимен & + & - & 30 & 4-Терпениол & + & + \\
\hline 5 & Камфен & + & + & 31 & Додеканон & + & - \\
\hline 6 & бета-Пинен & + & + & 32 & альфа-Терпениол & + & + \\
\hline 7 & бета-Мирцен & + & + & 33 & Деканаль & + & - \\
\hline 8 & Гераниол & + & - & 34 & Кариофиллен & + & - \\
\hline 9 & гамма-Терпинен & + & - & 35 & 6-Додеканон & + & - \\
\hline 10 & p-Цимен & + & + & 36 & альфа-Хумулен & + & - \\
\hline
\end{tabular}




\begin{tabular}{|c|c|c|c|c|c|c|c|}
\hline 1 & 2 & 3 & 4 & 5 & 6 & 7 & 8 \\
\hline 11 & 1,8-Цинеол & + & + & 37 & Ледол & + & - \\
\hline 12 & 2-Нонанон & + & - & 38 & Борнил ацетат & + & + \\
\hline 13 & 2-р-Толилпропан & + & - & 39 & 2-Камфанил ацетат & + & - \\
\hline 14 & бета-Линалоол & + & + & 40 & p-Винилгваякол & + & - \\
\hline 15 & Карен & + & - & 41 & Виридифлорол & + & + \\
\hline 16 & альфа-Туйон & + & + & 42 & 1-Тридеканол & + & - \\
\hline 17 & бета-Туйон & + & + & 43 & бета-Кариофиллен & + & + \\
\hline 18 & 3-Туйол & + & - & 44 & $\begin{array}{c}\text { Оксид бета- } \\
\text { кариофиллена }\end{array}$ & + & - \\
\hline 19 & Изотуйол & + & - & 45 & альфа-Кариофиллен & + & - \\
\hline 20 & Изоборнеол & + & - & 46 & Аромадендрен & + & - \\
\hline 21 & Лимонен & + & - & 47 & Аромадендрена оксид & + & - \\
\hline 22 & Камфора & + & + & 48 & цис-альфа-Бисаболлен & + & - \\
\hline 23 & Изоментон & + & - & 49 & 2-гексил-1-окатанол & + & - \\
\hline 24 & Изопинокамфон & + & - & 50 & Нонадеканол & + & - \\
\hline 25 & бета-Цитронерол & + & - & 51 & Скарнеол & + & - \\
\hline 26 & 3-Туйонол & + & - & 52 & 19-D-Торулусол & + & - \\
\hline
\end{tabular}

ВЭЖХ-ДМД-МС - определение компонентов фенольного состава в эфирномасличном сырье. Субкритическая экстракция БАВ при повышенных температуре и давлении позволяет одновременно извлекать также компоненты фенольной природы: коричные кислоты, флавоноиды, антоцианы, а также дитерпеновые химические соединения - карнозоловую кислоту, карнозол, розманол и другие биологически активные соединения.

По результатам ВЭЖХ-ДМД-МС анализа нами были определены концентрации некоторых фенольных соединений в экстрактах шалфея, выделенных субкритическим способом (таблица 2).

Таблица 2. Результаты определения фенольных соединений шалфея методом ВЭЖХДМД-МС

\begin{tabular}{|c|c|c|c|}
\hline Соединение & $\mathrm{t}_{\mathrm{r}}$, мин & $\lambda_{\max }, \mathrm{Hм}$ & $\begin{array}{c}\text { Концентрация компонента, мг/г } \\
\text { сырья }\end{array}$ \\
\hline Кофейная кислота & 9.5 & 323 & $0.066 \pm 0.008$ \\
\hline Лютеолин-7-О-глюкозид & 14.5 & 345 & $0.014 \pm 0.002$ \\
\hline $\begin{array}{c}\text { Лютеолин-7-О-бета-D- } \\
\text { глюкуронид }\end{array}$ & 15.6 & 345 & $0.29 \pm 0.03$ \\
\hline Розмариновая кислота & 17.3 & 327 & $0.078 \pm 0.009$ \\
\hline Карнозол & 28.1 & 284 & $0.09 \pm 0.01$ \\
\hline Карнозоловая кислота & 29.7 & 284 & $0.023 \pm 0.003$ \\
\hline
\end{tabular}

\section{Заключение}

Экстракт, полученный с применением субкритической экстракции при повышенных температуре и давлении, по компонентному составу существенно отличается от экстракта, полученного традиционным гидродистилляционным способом. Существенным их отличием можно считать, что, наряду с эфирномасличными компонентами, данный способ позволяет одновременно извлечь и определить содержание фенольных соединений в экстракте. 
Исследования проводили при финансовой поддержке РФФИ

(проект № 18-33-00245 мол_а) с использованием научного оборудования ЦКП «Экологоаналитический иентр» Кубанского госуниверситета

\title{
Список литературы
}

1. Amorati R., Foti M., Valgimigli L. // J. Agric. Food Chem. 2013. Vol. 61. No 46. pp. 10835-10847.

2. Mannelli L.D.C., Micheli L., Maresca M., Cravotto G. et al. // Sci Rep. 2016. Vol. 6. No 34832. pp. 1-15.

3. Ben Farhat M., Jordan MJ., ChaouechHamada R., Landoulsi A. et al. // J. Agric. Food Chem. 2009. Vol. 57. No 21. pp. 10349-10356.

4. Dziurzynski T., Ludwiczuk A., Glowniak K. // Curr Issues Pharm Med Sci. 2013. Vol. 26. No 3. pp. 326-330.

5. Bahadori M., Salehi P., Sonboli A. // International Journal of Food Properties. 2017. Vol. 20. No 12. pp. 2974-2981.

6. Государственная Фармакопея РФ / 14 издание. 2018. Т. 3. С. 2383-2387.

7. Wei Z., Zhao R., Dong L., Zhao X. e al. // Industrial Crops and Products. 2018. Vol. 120. pp. 71-76.

8. Manouchehri R., Saharkhiz M., Karami A., Niakousari M. // Sustainable Chemistry and Pharmacy. 2018. Vol. 8. pp.76-81.

9. Hashemi S., Nikmaram N., Esteghlal S., Khaneghah A. et al. // Innovative Food Science and Emerging Technologies. 2017. Vol. 41. pp. 172-178.

10. Velickovic D., Milenovic D., Ristic S., Veljkovic V. // Biochemical Engineering Journal. 2008. Vol. 42. No 1. pp. 97-104.
11. Маркин В. И., Чепрасова М.Ю., Базарнова Н. Г. // Химия растительного сырья. 2014. №4. C. 21-42.

12. Okoh O.O., Sadimenko A.P., Afolayan A.J. // Food Chem. 2010. Vol. 120. No 1. pp. 308-312.

13. Paul K., Bhattacharjee P. // Journal of Essential Oil Bearing Plants. 2018. Vol. 21. No 2. pp. 10-24.

14. Bendif H., Adouni K., Miara M.D., Baranauskienè R. et al. // Food Chem. 2018. Vol. 260. pp. 289-298.

15. Pavlic B., Vidovi S., Vladi J., Radosavljevic R. et al. // The Journal of Supercritical Fluids. 2016. Vol. 116. pp. 36-45.

16. Khoddami A., Wilkes M.A., Roberts T.H. // Molecules, 2013. Vol. 18. No 2. pp. 23282375.

17. Милевская В.В., Темердашев 3.А., Бутыльская Т.С., Киселева Н.В. // Журнал аналитической химии. 2017. Т. 72. № 3. С. 273279.

18. Asamenew G., Asres K., Bisrat D., Mazumder A. et al. // Journal of Essential Oil Bearing Plants. 2017. Vol. 20. No 2. pp. 426437.

19. Kutlular O., Ozel M.Z. // Jeobp. 2009. Vol. 12. No 4. pp. 462-470.

20. El Euch S.K., Hassine D.B., Cazaux S., Bouzouita N. et al. // South African Journal of Botany. 2019. Vol. 120. pp. 253-260.

\section{Identification and determination of biologically active substances of sage (Salvia officinalis L.), obtained under subcritical extraction conditions}

\author{
Ryabokon' Lilya P., Milevskaya Victoria V., \\ Kiseleva Natalia V., Temerdashev Zaual A. \\ Kuban State University, Krasnodar
}

\begin{abstract}
The object of this study were sage leaves (Salvia officinalis L.) of the brand «Zelyonaya apteka», purchased at the store Travy Kavkaza in Goryachy Klyuch. This paper focuses on the applicability of an alternative method of extraction, identification, and determination of biologically active compounds of herbs by means of subcritical extraction. The aim of the study was to analyse the component composition of biologically active compounds of sage, obtained by subcritical extraction. The subcritical extraction of biologically active compounds of sage (Salvia officinalis L.) was performed using deionized water and 70\% ethanol
\end{abstract}


at the temperature of 100 to $250{ }^{\circ} \mathrm{C}$. The chromatographic determination of analytes in the sage extract was carried out by means of gas chromatography-mass spectrometry and liquid chromatography-mass spectrometry together a with solid-phase concentration technique. The analytes were then identified using standard samples and individual compounds. The conditions for the subcritical and solid-phase extraction of essential oil compounds and phenolic compounds from sage extract were optimised. The optimal temperature for extracting essential oil compounds from sage is $200{ }^{\circ} \mathrm{C}$. Higher temperatures result in degradation of the studied compounds and a lower effectiveness of extraction. The analytes were extracted into organic phase by means of solid-phase extraction using Strata C18-E, Strata X, and Oasis HLB sorbents. Essential oil compounds and phenolic compounds in the organic phase were obtained by subcritical extraction at an elevated temperature and pressure. The identified component composition of the extract obtained by subcritical extraction differs significantly from that of the compounds obtained by means of traditional hydrodistillation. It was determined that sage contains 52 essential oil compounds. As opposed to hydrodistillation, subcritical extraction allowed for concurrent extraction of phenolic compounds: cinnamic acids, flavonoids, and anthocyanins, as well as diterpenes. An advantage of the proposed method is that it allows the concurrent extraction and identification of essential oil compounds and phenolic compounds. The results of these study are of great interest for chemical studies of medicinal plant raw material.

Keywords: subcritical extraction, sage, chromatographic analysis, essential oil compounds, phenolic compounds, concentration

\section{References}

1. Amorati R., Foti M., Valgimigli L., J. Agric. Food Chem, 2013, Vol. 61, No 46, pp. 10835-10847. doi: 10.1021/jf403496k

2. Mannelli L.D.C., Micheli L., Maresca M., Cravotto G. et al., Sci Rep., 2016, Vol. 6, No 34832, pp. 1-15. doi: 10.1038/srep34832

3. Ben Farhat M., Jordan MJ., ChaouechHamada R., Landoulsi A. et al., J. Agric. Food Chem, 2009, Vol. 57, No 21, pp. 10349-10356. doi: 10.1021/jf901877x

4. Dziurzynski T., Ludwiczuk A., Glowniak K., Curr Issues Pharm Med Sci, 2013, Vol. 26, No 3, pp. 326-330. doi: 10.12923/j.2084980X/26.3/a. 19

5. Bahadori M., Salehi P., Sonboli A., International Journal of Food Properties, 2017, Vol. 20, No 12, pp. 2974-2981. doi: 10.1080/10942912.2016.1263862

6. Russian Pharmacopoeia 14., 2018. Vol. 3.

7. Wei Z., Zhao R., Dong L., Zhao X. et al., Industrial Crops and Products, 2018, Vol. 120, pp. 71-76. doi: 10.1016/j.indcrop.2018.04.058

8. Manouchehri R., Saharkhiz M., Karami A., Niakousari M., Sustainable Chemistry and Pharmacy, 2018, Vol. 8, pp.76-81. doi: 10.1016/j.scp.2018.03.002

9. Hashemi S., Nikmaram N., Esteghlal S., Khaneghah A. et al., Innovative Food Science and Emerging Technologies, 2017, Vol. 41, pp. 172-178. doi: 10.1016/j.ifset.2017.03.003

10. Velickovic D., Milenovic D., Ristic S., Veljkovic V., Biochemical Engineering Journal, 2008. Vol. 42, No 1, pp. 97-104. doi: 10.1016/j.bej.2008.06.003
11. Markin V. I., Cheprasova M.Y., Bazarnova N.G, Khimiya rastitel'nogo syr'ya, 2014, No 4, pp. 21-42. doi: 10.14258/jcprm.201404597

12. Okoh O.O., Sadimenko A.P., Afolayan A.J., Food Chem, 2010, Vol. 120, No 1, pp. 308-312. doi: 10.1016/j.foodchem.2009.09.084

13. Paul K., Bhattacharjee P., Journal of Essential Oil Bearing Plants, 2018, Vol. 21, No 2, pp. 10-24. doi: 10.1080/0972060X.2018.1439406 et al., Food Chem, 2018, Vol. 260, pp. 289-298. doi: 10.1016/j.foodchem.2018.03.108

15. Pavlic B., Vidovi S., Vladi J., Radosavljevic R. et al., The Journal of Supercritical Fluids, 2016, Vol. 116, pp. 36-45. doi: 10.1016/j.supflu.2016.04.005

16. Khoddami A., Wilkes M.A., Roberts T.H., Molecules, 2013, Vol. 18, No 2, pp. 2328-2375. doi: 10.3390/molecules18022328

17. Milevskaya V.V., Temerdashev Z. A., Butyl'skaya T.S., Kiseleva N.V., Journal of Analytical Chemistry, 2017, Vol. 72, No 3, pp. 273-279. doi: 10.7868/S0044450217030112

18. Asamenew G., Asres K., Bisrat D., Mazumder A., Lindemann P., Journal of Essential Oil Bearing Plants, 2017, Vol. 20, No 2, pp. 426-437. doi: 10.1080/0972060X.2017.1287008

19. Kutlular O., Ozel M.Z., Journal of Essential Oil Bearing Plants, 2009, Vol. 12, No 4, pp. 462-470. doi: 10.1080/0972060X.2009.10643745

20. El Euch S.K., Hassine D.B., Cazaux S., Bouzouita N. et al., South African Journal of Botany, 2019, Vol. 120, pp. 253-260. doi: 10.1016/j.sajb.2018.07.010 
Рябоконь Лилия Петровна - магистрант 2 года обучения кафедры аналитической химии, Кубанский государственный университет, Краснодар

Милевская Виктория Васильевна - старший преподаватель кафедры аналитической химии, к.Х.н., Кубанский государственный университет, Краснодар

Киселева Наталия Владимировна - доцент кафедры аналитической химии, к.х.н., Кубанский государственный университет, Краснодар

Темердашев Зауаль Ахлоович - зав. кафедрой аналитической химии, д.х.н., Кубанский государственный университет, Краснодар
Ryabokon' Lilya P. - postgraduate of the Department of Analytical Chemistry, Kuban State University, Krasnodar, e-mail: lilyar6@yandex.ru

Milevskaya Victoria V. - Ph.D. in Chemistry, Art. Lecturer Department of Analytical Chemistry, Kuban State University, Krasnodar, e-mail: milevskaya_victoriya@mail.ru

Kiseleva Natalia V. - Ph.D. (chemistry), associate prof., department of analytical chemistry, Kuban State University, Krasnodar, e-mail: lab284b@mail.ru

Temerdashev Zaual A. - doctor of chemical sciences, professor and the Head Department of Analytical Chemistry, Kuban State University, Krasnodar, e-mail: temza@kubsu.ru 